\title{
Sanitary safety of the 2021 French Intensive Care Society medical conference: a case/control study
}

SRLFTrial Group*

\begin{abstract}
Background: In-person mass gathering events (MGE) are returning after a period of restrictions, yet few prospective scientific evaluations of their safety are available.

Methods: Prospective observational study, including both attendees of the French Intensive Care Society (FICS) annual meeting held in Paris between June the 9th and June the 11th, 2021 and matched controls (healthcare professionals who stayed in the ICU during the conference). SARS-CoV-2 lateral flow test was performed on day 7. Follow-up occurred until day 21.

Results: Out of the 1824 healthcare professionals attending the congress (all of which fulfilled legal requirements: 7 days or more following a second dose of vaccine or a negative PCR test performed within less than $72 \mathrm{~h}$ ), 520 (28.5\%) agreed to participate. Follow-up data were received for 216 (41.5\%) out of the 520 included attendees, and for 191 matched controls. No positive SARS-CoV-2 lateral flow test was reported in the attendees or in the matched controls. The probability of SARS-CoV-2 infection during the MGE was less than $1.7 \%$ in the attendees (95\% confidence interval $[0 ; 1.7 \%])$, less than $2 \%$ in the controls $(95 \% \mathrm{Cl}[0 ; 2 \%])$ and the difference in probabilities of infection was less than $1.9 \%(95 \% \mathrm{Cl}[0 ; 1.9 \%])$.

Conclusion: During a low incidence period, in this population of congress attendees screened for SARS-CoV-2 by a lateral flow test at day 7, no positive cases could be documented, no concomitant infection occurred in the matched controls; suggesting no extra risk of infection during the MGE.

Trial Registration: ClinicalTrial.gov, \#NCT04918160.
\end{abstract}

Keywords: Mass gathering event, SARS-CoV-2, COVID-19, Transmission, Infectious disease, Prevention

\section{Introduction}

Non-pharmacological interventions aimed at preventing SARS-CoV-2 transmission include contact tracing and quarantine of cases, up to lockdowns when rates of infection are higher as well as physical distancing; which includes limiting the occurrence of mass gathering events (MGE), [1]. Indeed, several outbreaks of SARS-CoV-2

\footnotetext{
*Correspondence: jeanbaptiste.lascarrou@chu-nantes.frService de Médecinadditie Intensive Réanimation, Centre Hospitalier Universitaire, 44093 Nantes Cedex 1, France

Full list of author information is available at the end of the article
}

were associated with MGE [2], linked to the attendance of asymptomatic carriers who may nevertheless transmit the virus. Indeed, SARS-CoV-2 transmissibility begins 2 to 3 days before symptom onset; nearly half of all transmissions arise through contact with asymptomatic individuals [3]. Additionally, reverse transcriptase-polymerase chain reaction (RT-PCR) test results are delayed, making it an impractical tool for mass testing strategies prior to a MGE. Alternative point-of-care diagnostic methods include antigen-detecting rapid diagnostic tests. Lateral flow tests (LFT) detect the nucleocapsid protein antigen of SARS-CoV-2 and provide results within 
30 min. LTF may be self-administered at home, enabling the rapid identification of people infected by the virus.

Despite improved capacities of detecting SARS-CoV-2 infections, few prospective assessments of the sanitary safety of mass gathering events (MGE) have been performed. In a pivotal study conducted in Spain, out of 465 spectators of a live music event, 13 (3\%) subjects were found to be positive for SARS-CoV-2 antigen testing [4]. The same team found in a subsequent study, found that out of 5000 subjects willing to spectate a live music event, 6 were tested positive for SARS-CoV-2 [5]. However, these observations occurred prior to mass vaccination of the population. In France, Delaugerre et al. in a randomized controlled trial with almost 4000 attendees, found than participation in a large, indoor, live gathering without physical distancing was not associated with increased SARS-CoV-2 transmission risk, provided a comprehensive preventive intervention was implemented [6].

Among MGE, medical conferences are of special interest because they bring together healthcare workers who are on the frontline of the fight against COVID-19. Said healthcare workers are exposed on a day-to-day basis to SARS-CoV-2 both in their COVID-19 units and out of hospital. Additionally, healthcare workers are essential to provide adequate care for COVID-19 infected patients; sickness leave due to SARS-CoV-2 exposure or infection may weaken already overstretched healthcare system. This is especially true in intensive care units (ICU) [7]. The sanitary safety of medical congresses is thus of utmost importance.

To assess potential transmission of SARS-CoV-2 during the French Intensive Care Society annual meeting, we conducted a prospective study with systematic LFT tests performed by attendees and controls 7 days after the event. This event took place in a context where vaccination and/or negative SARS-CoV-2 testing were required for attendance.

\section{Patients and methods Study design}

We conducted a prospective observational study, including both attendees to the French Intensive Care Society (FICS/SRLF) annual meeting held in Paris between June 9 and June 11, 2021 and matched controls. Indeed, given the specific exposure of ICU healthcare professionals, inclusion of a control grouped seemed mandatory. Matched controls were colleagues of attendees who stayed in ICU throughout the medical conference. Data were collected during the meeting and up to day 21 after the meeting. This report follows the STROBE guidelines [7].

\section{Requirements to attend the congress}

French regulation in place at the time of congress mandated each attendee to comply with at least one the following requirements:

- 7 days after 2 nd administration for dual dose vaccines (Pfizer@, Moderna@, AstraZeneca $\odot$ );

- 28 days after administration for single dose vaccines (Janssen/Johnson \& Johnson $\odot)$;

- 7 days after administration of the vaccine for people who had previously contracted COVID-19 (only 1 injection) more than 6 months ago;

- Recovery from COVID-19 attested by the result of a positive SARS-CoV-2 RT-PCR or antigenic test dating from at least 15 days and less than 6 months (associated with a limited risk of reinfection with COVID-19) [8].

- Proof of a negative SARS-CoV-2 RT-PCR or antigenic detection test performed within less than $48 \mathrm{~h}$.

Other mitigation strategies during the congress were implemented and included: availability of hand sanitizers, mandatory wearing of surgical face masks and adequate ventilation of all congress areas. Ventilation of congress areas was assessed by measuring average carbon dioxide (CO2) levels using a $\mathrm{CO} 2$ Monitoring device Air Therm (La Mode, London, UK).

\section{Participant selection}

Inclusion criteria for the attendees were:

- Healthcare professional,

- Absence of COVID-19 symptoms over the 2 weeks prior to inclusion,

- Not being contact of a case of COVID-19 over the 2 weeks prior to inclusion,

- Attending at least one day of the FICS annual meeting (June 9-11 2021).

Exclusion criteria were:

- Non-healthcare professionals,

- Refusal to participate,

- Guardianship or tutorship,

- Absent affiliation to the French social security.

Controls were recruited by the attendees. The same inclusion and exclusion criteria were applied to controls except that they did not participate to the annual meeting. Controls were matched to attendees in terms of gender, age ( $<$ or $>40$ years), profession (medical doctor, nurse, 
nurse assistant, other) and vaccine status (complete, partial, non-vaccinated).

\section{Self-administered LFT SARS-CoV-2 tests}

LFT for SARS-CoV-2 aims to detect infection by recognizing viral proteins. Most LFT use specific labeled antibodies attached to a nitrocellulose matrix strip to capture viral antigens. The Flowflex SARS-CoV-2 Antigen Rapid Test is a lateral flow chromatographic immunoassay for the qualitative detection of the nucleocapsid protein antigen from SARS-CoV-2 in nasal and nasopharyngeal swab specimens directly from individuals who are suspect of COVID19. Successful binding of the antibodies to the antigen is visually detected through the appearance of a line on the matrix strip. The Flowflex SARS-CoV-2 Antigen Rapid test provides results within $30 \mathrm{~min}$.

LFTs were freely provided at the time of inclusion. $7 \pm 1$ days after the attendee's last day of attendance, the attendee and his control were asked to perform a LFT.

\section{Data collection}

Standardized forms were used to record the following data: participant's baseline characteristics (age, gender, height, weight) and COVID-19 status (previous COVID-19 infection and date of occurrence), risk factors of developing a severe form of COVID-19 (see Additional file 4: Table S1), anti-SARS-CoV-2 vaccination status (number of doses, date of injection, type of vaccine), results of the day 7 selfadministered LFT and occurrence of COVID-19 symptoms and/or need of medical assistance for a COVID-19 infection over a three week period following the congress. Follow-up was obtained at day 21 for each participant and control.

\section{Ethics}

The study was approved by French Infectious Disease Society ethics committee (CERMIT $N^{\circ}$ COVID 2021-08) and was registered on ClinicalTrials.gov (\#NCT03600181). Written information was delivered to all participants. All participants entered the study following oral consent.

\section{Outcomes}

The primary endpoint was the prevalence of attendees with a positive COVID-19 self-administration LFT at day 7 of participation to the congress.

Secondary objectives were:

- COVID-19 prevalence among controls at Day 7,

- Proportion of congress attendees with COVID-19 symptoms by Day 21 ,
- Proportion of congress attendees requiring COVID19-related appointment with a general practitioner by Day 21,

- Proportion of congress attendees with COVID-19-related emergency department visits by Day 21,

- Proportion of conference attendees with COVID19-related hospitalization by Day 21.

\section{Sample size}

Given the exploratory nature of our study, we did not calculate a sample size. We aimed at including a convenience sample of 500 attendees and 500 controls (1000 participants).

\section{Statistical analysis}

Qualitative variables were described as number (\%) and quantitative variables as mean \pm SD if normally distributed and as median [25th-75th percentile] otherwise. Matching factors between attendees and controls were compared by means of Fisher tests. All tests were two-tailed with a significance level of 0.05 .

Confidence interval for the probabilities of being infected for attendees and controls was performed by means of one-tailed exact 95\% confidence interval for binomial proportions. For the difference in proportions, we used the simple "add 2 success, add 2 failures" method [9].

All statistical analyses were performed using $\mathrm{R}$ statistical software version 4.0.3.

\section{Results}

\section{Baseline characteristics}

Out of the 1824 healthcare workers attending the congress, 520 (28.5\%) agreed to participate. Baseline characteristics and comparison with attendees who did not participate are depicted in Table 1. Regional origins of both groups are presented on Additional file 1: Figure S1. Briefly, participants were mainly female and nurses and we observed some regional disparities.

\section{Follow-up}

Follow-up data were obtained for 216 (42\%) out of 520 participants, and for 191 controls. Characteristics of attendees and controls were well matched except for the profession, with a higher percentage of medical doctors among the attendees as compared to nurses (i.e., less medical doctors succeed in recruiting controls) (Table 2, Fig. 1 and Additional file 2: Figure S2).

\section{Primary outcome}

No positive COVID-19 LFT was reported in the attendee's group. The $95 \%$ confidence interval estimate of the 
Table 1 Comparison of included and not included participants of the congress

\begin{tabular}{|c|c|c|c|}
\hline & $\begin{array}{l}\text { Included } \\
(\mathrm{n}=520)\end{array}$ & $\begin{array}{l}\text { Not included } \\
(n=1304)\end{array}$ & $\mathbf{P}$ \\
\hline Gender, male, n (\%) & $229(44)$ & $649(49.8)$ & 0.031 \\
\hline Professional category, n (\%) & & & $<0.001$ \\
\hline Doctor or resident & $281(54)$ & $700(53.7)$ & \\
\hline Nurse & $153(29.4)$ & $319(24.5)$ & \\
\hline Assistance nurse & $17(3.3)$ & $36(2.8)$ & \\
\hline Physiotherapists & $34(6.5)$ & $60(4.6)$ & \\
\hline Others & $35(6.7)$ & 189(14.5) & \\
\hline Age, years, mean $\pm S D$ & $38.2 \pm 11.0$ & $39 \pm 11.9$ & 0.26 \\
\hline Country, n (\%) & & & 0.654 \\
\hline France & $406(78.1)$ & $1208(92.6)$ & \\
\hline Others* & $26(5.0)$ & $88(6.7)$ & \\
\hline Not known & $88(16.9)$ & $8(0.6)$ & \\
\hline $\begin{array}{l}\text { French administrative region, } \\
\mathrm{n}(\%)\end{array}$ & & & $<0.001$ \\
\hline Auvergne-Rhône-Alpes & $45(8.7)$ & $109(8.3)$ & \\
\hline Bourgogne-Franche-Comté & $16(3.1)$ & $43(3.2)$ & \\
\hline Bretagne & $2(0.4)$ & $20(1.5)$ & \\
\hline Centre-Val de Loire & $10(1.9)$ & $34(2.6)$ & \\
\hline Grand Est & $40(7.6)$ & $81(6.2)$ & \\
\hline Hauts-de-France & $43(8.2)$ & $81(6.2)$ & \\
\hline Ile-de-France & $139(26.7)$ & $613(47.0)$ & \\
\hline Normandie & $20(3.8)$ & $58(4.4)$ & \\
\hline Nouvelle-Aquitaine & $28(5.3)$ & $75(5.7)$ & \\
\hline Occitanie & $17(3.2)$ & $53(4.0)$ & \\
\hline Outre-mer & $4(0.7)$ & $10(0.7)$ & \\
\hline Pays de la Loire & $30(5.7)$ & $56(4.3)$ & \\
\hline Provence-Alpes-Côte d'Azur & $36(6.9)$ & $47(3.6)$ & \\
\hline Unknown & $90(17.3)$ & $24(1.8)$ & \\
\hline
\end{tabular}

* Some participants came from French-speaking countries such as Belgium or Switzerland (not detailed in case report form)

The percentages may not total 100 because of rounding. Missing data not included in statistical analysis

probability of infection during the congress for attendees ranged between 0 and $1.7 \%$.

\section{Secondary outcomes}

No positive COVID-19 LFT was reported in the control group either, leading to an estimated $95 \%$ confidence interval probability of contamination during the congress between 0 and $2 \%$. Accordingly, we computed the confidence interval for the difference in probability of infection between attendees and controls using the "add 2 success and add 2 failures", yielding a difference in the range $[-1.9 ; 1.9 \%]$ (95\% confidence interval). Secondary outcomes are presented in Table 3. No significant difference between attendees and controls were found except for the probability that the LFT was performed $(98.1 \%$
Table 2 Comparison of attendees and controls

\begin{tabular}{|c|c|c|c|}
\hline & $\begin{array}{l}\text { Attendees } \\
(\mathrm{N}=216)\end{array}$ & $\begin{array}{l}\text { Controls } \\
(\mathrm{N}=191)\end{array}$ & $\mathbf{P}$ \\
\hline Gender, n, \% & & & 0.84 \\
\hline Male & $101(46.8)$ & $88(46.1)$ & \\
\hline Female & $109(50.5)$ & 99 (51.8) & \\
\hline Missing & $6(2.8)$ & $4(2.1)$ & \\
\hline Profession & & & 0.001 \\
\hline Doctor & $131(60.6)$ & $100(52.4)$ & \\
\hline Nurse & $55(25.5)$ & $46(24.1)$ & \\
\hline Assistant nurse & $2(0.9)$ & $9(4.7)$ & \\
\hline Physiotherapist & $19(8.8)$ & $16(8.4)$ & \\
\hline Others & $2(0.9)$ & $15(7.9)$ & \\
\hline Missing & $7(3.2)$ & $5(2.6)$ & \\
\hline Age & & & 0.47 \\
\hline$<50$ years & $160(74.1)$ & $149(78.0)$ & \\
\hline$\geq 50$ & $49(22.7)$ & $38(19.9)$ & \\
\hline Missing & $7(3.2)$ & $4(2.1)$ & \\
\hline History of COVID-19 & & & * \\
\hline No & $216(100)$ & $171(89.5)$ & \\
\hline Yes & $0(0)$ & $2(1.0)$ & \\
\hline Missing & $0(0)$ & $18(9.4)$ & \\
\hline Vaccinal status (number of dose) ${ }^{\$}$ & & & 0.77 \\
\hline 0 dose & $8(3.7)$ & $10(5.2)$ & \\
\hline 1 dose & $38(17.6)$ & $32(16.8)$ & \\
\hline 2 doses & $162(75.0)$ & $145(75.9)$ & \\
\hline Missing & $8(3.7)$ & $4(2.1)$ & \\
\hline Vaccinal status (binary) & & & 0.90 \\
\hline Complete & $161(74.5)$ & $144(75.4)$ & \\
\hline Incomplete & $38(17.6)$ & $32(16.8)$ & \\
\hline Missing & $17(7.9)$ & $15(7.9)$ & \\
\hline BMI & & & 0.22 \\
\hline $\mathrm{BMI}<18.5$ & $2(0.9)$ & $4(2.1)$ & \\
\hline $18.5 \leq \mathrm{BMI} \leq 25$ & $149(69.0)$ & $116(60.7)$ & \\
\hline $25 \leq \mathrm{BMI} \leq 30$ & $44(20.4)$ & $49(25.7)$ & \\
\hline $\mathrm{BMI}>30$ & $14(6.5)$ & $18(9.4)$ & \\
\hline Missing & $7(3.2)$ & $4(2.1)$ & \\
\hline Vulnerability & & & 0.52 \\
\hline No & $199(92.1)$ & $157(82.2)$ & \\
\hline Yes & $11(5.1)$ & $12(6.3)$ & \\
\hline Missing & $6(2.8)$ & $22(11.5)$ & \\
\hline
\end{tabular}

$B M I$ body mass index

${ }^{*}$ Not enough events for statistical comparison

$\$$ Legal requirement to attend congress was 7 days after 2 doses or PCR test less than 2 days, explaining medium rate of 2 doses vaccination status

Missing data not included in statistical analysis

vs 80.6\%; $\mathrm{P}<0.001)$. $\mathrm{CO} 2$ levels throughout the congress were median [IQR] 594 [561-687] ppm during the event (Additional file 3: Figure S3). 

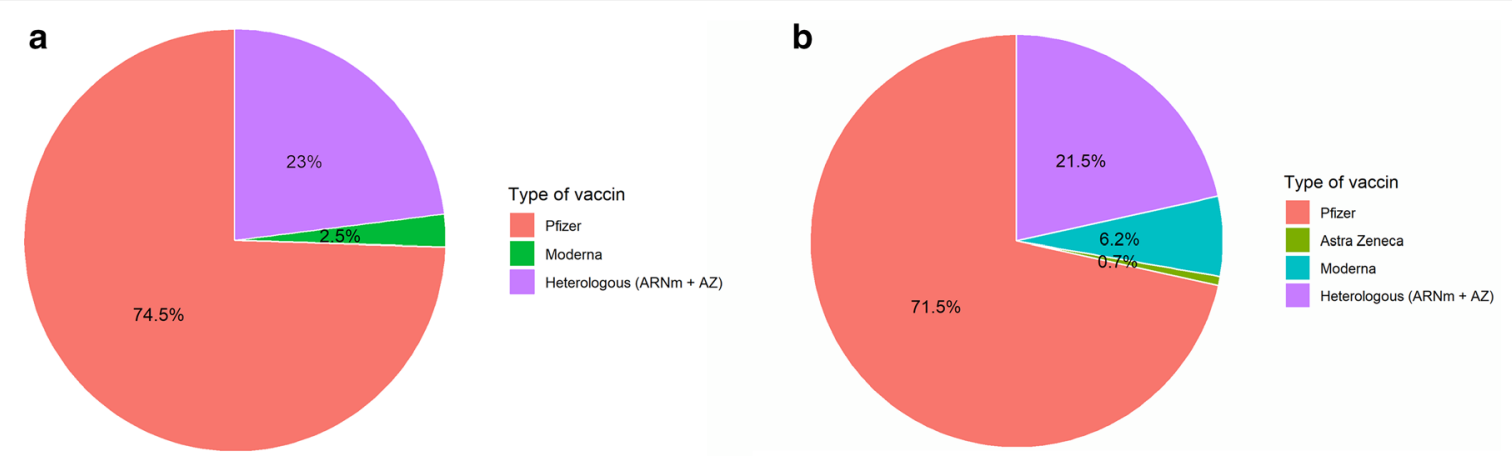

Fig. 1 Distribution of vaccine type. a Attendees ( $n=200,16$ patients with missing value). b Controls( $n=191,15$ patients with missing value)

Table 3 Secondary outcomes

\begin{tabular}{lll}
\hline & $\begin{array}{l}\text { Attendees } \\
(\mathbf{N}=\mathbf{2 1 6})\end{array}$ & $\begin{array}{c}\text { Controls } \\
(\mathbf{N}=\mathbf{1 9 1})\end{array}$ \\
\hline $\begin{array}{l}\text { Symptoms at day } 7, \mathrm{n}(\%) \\
\text { No }\end{array}$ & $214(99.0)$ & $172(90.0)$ \\
Yes & $1(0.5)$ & $0(0.0)$ \\
Missing & $1(0.5)$ & $19(10.0)$ \\
AutoLTF performed, $\mathrm{n}(\%)$ & & $18(9.4)$ \\
No & $4(1.9)$ & $154(80.6)$ \\
Yes & $212(98.1)$ & $19(9.9)$ \\
Missing & $0(0.0)$ & $175(91.6)$ \\
Symptoms until day 21, $\mathrm{n}(\%)$ & & $0(0.0)$ \\
No & $214(99.1)$ & $16(8.4)$ \\
Yes & $2(0.9)$ & $163(85.3)$ \\
Missing & $0(0.0)$ & $12(6.3)$ \\
Additional test performed at day 21, $\mathrm{n}(\%)$ & & $16(8.4)$ \\
No & $198(91.7)$ & 0.99 \\
Yes & $18(8.3)$ & $173(90.6)$ \\
Missing & $0(0.0)$ & $0(0.0)$ \\
Need for medical consults until day 21, $\mathrm{n}(\%)$ & & $18(9.4)$ \\
No & $216(100)$ & 0.70 \\
Yes & $0(0.0)$ & 0.01 \\
Missing & $0(0.0)$ & - \\
\hline
\end{tabular}

Missing data not included in statistical analysis

\section{Discussion}

We found that, in the current area of highly effective vaccines, SARS-CoV-2 transmission during a medical congress was extremely low and similar in controls who did not attend the conference.

A recent review of published studies focusing on the impact of mitigation strategies during the COVID-19 pandemic [10] concluded that "there is currently limited evidence on the effectiveness of measures to prevent SARS-CoV-2 transmission at mass gatherings". Our results are in line with previous studies on the safety of mass gathering events while respecting physical distancing and simple measures of hygiene. In an earlier study, Flury et al. included 196 participants out of the 365 attendees of the Swiss Societies of Infectious Diseases and Hospital Hygiene congress [11]. The authors found that 5 participants presented a positive SARS-CoV-2 serology at follow-up, all whom were already positive at baseline. In the study by Revollo et al. [4], out of the 495 participants attending a music event, none presented a positive PCR at day 8 , resulting in a Bayesian estimate for the incidence between the exposed and the non-exposed 
of $-0.15 \%$ ( $95 \% \mathrm{CI}-0.72$ to 0.44$)$. In our study, the frequentist estimate for the difference in incidence between the participants and the controls ranged between -2 to $2 \%$.

In addition to these results, our study highlights several challenges encountered in epidemiological studies assessing SARS-CoV-2 transmission. First, participation in a scientific evaluation of transmission is challenging, even in a population of healthcare workers confronted to COVID-19 since the beginning of the pandemic. Indeed, only around 30\% of healthcare workers attending the conference agreed to be included and less than half of these self-administered their LFT at day 7 and reported their status after the congress. This low feedback from participants in the context of self-delivered COVID-19 testing must be anticipated especially for self-funded research study. Second, we found that the recruitment of controls by participants allowing a fair comparison of infectious disease contamination rates is possible for participants who are healthcare workers in departments highly involved in clinical research [12], with almost as many controls as attendees recruited. We also showed that COVID-19 LFT can be self-performed by participants without major technical challenge. These tests could thus be used to mitigate the risk of COVID19 transmission in other settings. Indeed, although LFT are less sensitive than COVID-19 PCR and despite commercial kits displaying variable performance, their cost is reduced compared to PCR, greatly facilitating mass testing. The sensitivity of the LFT used in this study was $94.5 \%$, i.e., one of the best tests available at the time of the study [13]. In a study of 5,869 asymptomatic adults, Garcia-Finana et al. found that LFT were likely to detect a minimum of 3/5 and at most 998 out of every 1,000 subjects with a positive RT-qPCR test result and a high viral load [14]. We chose to perform LFT at day 7, since it was the best time window to detect SARS-CoV-2 transmission [15]. Our follow-up rate was $42 \%$ (216/520), similar to previous reports, i.e., between 13 and 66\% [16]. Lastly, $\mathrm{CO}_{2}$ levels measured during the event were broadly lower than recommended (between 600 to 1500 parts per million) $[17,18]$ indicating that the venue was sufficiently ventilated.

In addition, limitations due to the low rate of attendee recruitment and feed-back from participants, and the generalizability of our study must be discussed. First, our study was underpowered to detect a small but potentially clinically relevant difference due to the relatively low incidence of COVID-19 cases in France (40 cases/100.000) and Great Paris area (65 cases/100.000) at the time of the congress. Second, at the time of the congress, the SARSCoV-2 alpha variant was still dominant; our results may therefore not be true faced with delta or any other highly transmissible variant. Third, our study must be interpreted in the context of this specific mass event: young age of the participants and high rate of participants within 6 months of a complete vaccination scheme. Last, absence of randomization or of stratification by region or by profession, limit causal inference between congress attendance and risk of SARS-CoV-2 transmission.

\section{Conclusion}

In our study of a medical congress, screening for SARS$\mathrm{CoV}-2$ transmission by LFT at day 7, identified no positive cases among congress attendees or matched controls. In the context of low overall SARS-CoV-2 incidence and a predominant alpha variant, we found than mass event gathering can be safely performed if adequate mitigations procedures are applied before and during the congress.

\section{Supplementary Information}

The online version contains supplementary material available at https://doi. org/10.1186/s13613-022-00986-x.

Additional file 1: Figure S1. Graphic representation of attendees and participants.

Additional file 2: Figure S2. Distribution of vaccine type for fully vaccinated.

Additional file 3: Figure S3. Evolution of $\mathrm{CO} 2$ in the meeting area.

Additional file 4: Table S1. Vulnerability criteria.

\section{Acknowledgements}

We thank Alexandra Bernard (SRLF, Paris, France), Damien Le Marec (Europa Grou) and Mathieu Lloung (SRLF, Paris, France). SRLF/FICS Trial group writing committee: Pierre-Yves Boelle, Institut Pierre Louis d'Epidemiologie et de Santé Publique Paris (France), Guillaume Decormeille, Service de Réanimation polyvalente, Toulouse (France), Bertrand Hermann, Service de Médecine Intensive Réanimation, Hôpital Européen George Pompidou Paris (France), Nicholas Heming, Medecine Intensive Reanimation, Centre Hospitalier Universitaire, Garche (France), Gwenaelle Jacq, Medecine Intensive Reanimation, Centre Hospitalier, Versailles (France), Toufik Kamel, Medecine Intensive Reanimation, Centre Hospitalier Regional, Orleans (France), Jean-Baptiste Lascarrou, Service de Médecine Intensive Réanimation, Centre Hospitalier Universitaire Nantes (France), Eric Maury, Medecine Intensive Reanimation, Centre Hospitalier Universitaire Saint Antoine, Paris (France), Laurent Papazian, Medecine Intensive Reanimation, Centre Hospitalier Universitaire, Marseille (France), Gael Piton, Medecine Intensive Reanimation, Centre Hospitalier Universitaire, Besancon (France), Laurent Poiroux, Medecine Intensive Reanimation, Centre Hospitalier Universitaire, Angers (France), Julien Ramillon, Institut Pierre Louis d'Epidemiologie et de Santé Publique Paris (France), Anahita Rouze, Medecine Intensive Reanimation, Centre Hospitalier Universitaire, Lille (France)

\section{Authors' contributions}

Study design, development and study setup were performed by BH, JBL, JR. Site setup, subject enrolment, data collection and research governance were performed by all authors. JR performed the statistical analysis. Initial draft of the manuscript was by BH, JBL and JR. All authors reviewed and commented on this and subsequent versions of the manuscript. All authors vouch for the accuracy and completeness of the data and analyses, and for the fidelity of the trial to the protocol. All authors read and approved the final manuscript.

\section{Funding}

Funded by SRLF/FICS. 


\section{Availability of data and materials}

The study data will be made available upon reasonable request to the Research Commission of the French Intensive Care Society.

\section{Code availability}

Not applicable.

\section{Declarations}

Ethics approval and consent to participate

The study was approved by the ethics committee of the French Infectious Disease Society (No. IRB00011642) and was registered on ClinicalTrial.gov (\#NCT04918160). Informed consent was obtained from each participant and control before study inclusion.

\section{Consent for publication}

Not applicable.

\section{Competing interests}

None.

\section{Author details}

${ }^{1}$ Service de Médecinadditie Intensive Réanimation, Centre Hospitalier Universitaire, 44093 Nantes Cedex 1, France.

Received: 8 December 2021 Accepted: 20 January 2022

Published online: 11 February 2022

\section{References}

1. Coronavirus [Internet]. [cited 2021 Sep 9]. https://www.who.int/weste rnpacific/health-topics/coronavirus

2. Domènech-Montoliu S, Pac-Sa MR, Vidal-Utrillas P, Latorre-Poveda M, Del Rio-González A, Ferrando-Rubert S, et al. Mass gathering events and COVID-19 transmission in Borriana (Spain): a retrospective cohort study. PLOS ONE. 2021;16:e0256747.

3. Meyerowitz EA, Richterman A, Bogoch II, Low N, Cevik M. Towards an accurate and systematic characterisation of persistently asymptomatic infection with SARS-CoV-2. Lancet Infect Dis. 2021;21:e163-9.

4. Revollo B, Blanco I, Soler P, Toro J, Izquierdo-Useros N, Puig J, et al. Sameday SARS-CoV-2 antigen test screening in an indoor mass-gathering live music event: a randomised controlled trial. Lancet Infect Dis [Internet]. 2021 [cited 2021 Sep 9]. https://www.sciencedirect.com/science/article/ pii/S1473309921002681

5. Llibre JM, Videla S, Clotet B, Revollo B. Screening for SARS-CoV-2 antigen before a live indoor music concert: an observational study. Ann Intern Med. 2021. https://doi.org/10.7326/M21-2278.

6. Delaugerre C, Foissac F, Abdoul H, Masson G, Choupeaux L, Dufour E, et al. Prevention of SARS-CoV-2 transmission during a large, live, indoor gathering (SPRING): a non-inferiority, randomised, controlled trial. Lancet Infect Dis. 2021;0. https://www.thelancet.com/journals/laninf/article/PIIS1 473-3099(21)00673-3/fulltext

7. Arabi YM, Azoulay E, Al-Dorzi HM, Phua J, Salluh J, Binnie A, et al. How the COVID-19 pandemic will change the future of critical care. Intensive Care Med. 2021:47:282-91.

8. Everything about the sanitary pass [Internet]. [cited $2021 \mathrm{Sep} 10]$. https:// www.service-public.fr/particuliers/actualites/A15121

9. Agresti A, Caffo B. Simple and effective confidence intervals for proportions and differences of proportions result from adding two successes and two failures. Am Stat. 2000;54:280-8.

10. Walsh KA, Tyner B, Broderick N, Harrington P, O'Neill M, Fawsitt CG, Cardwell K, Smith SM, Connolly MA, Ryan M. Effectiveness of public health measures to prevent the transmission of SARS-CoV-2 at mass gatherings: a rapid review. Rev Med Virol. 2021;13:e2285. https://doi.org/10.1002/rmv. 2285.

11. Flury D, Sumer J, Albrich W, Kahlert C, Mueller N, Risch L, et al. Safety evaluation of a medical congress held during the COVID-19 pandemica prospective cohort [Internet]. 2021 [cited 2021 Oct 25]. https://europ epmc.org/article/PPR/PPR267336
12. Tonelli MR, Curtis JR, Guntupalli KK, Rubenfeld GD, Arroliga AC, Brochard $L$, et al. An official multi-society statement: the role of clinical research results in the practice of critical care medicine. Am J Respir Crit Care Med. 2012;185:1117-24.

13. Scheiblauer H, Filomena A, Nitsche A, Puyskens A, Corman V, Drosten C, Zwirglmaier K, Lange C, Emmerich P, Mueller M, Knauer O. Comparative sensitivity evaluation for 122 CE-marked SARS-CoV-2 antigen rapid tests. medRxiv. 2021. https://doi.org/10.1101/2021.05.11.21257016v1.

14. García-Fiñana M, Hughes DM, Cheyne CP, Burnside G, Stockbridge M, Fowler TA, et al. Performance of the Innova SARS-CoV-2 antigen rapid lateral flow test in the Liverpool asymptomatic testing pilot: population based cohort study. BMJ. 2021;374:n1637.

15. Brümmer LE, Katzenschlager S, Gaeddert M, Erdmann C, Schmitz S, Bota $M$, et al. Accuracy of novel antigen rapid diagnostics for SARS-CoV-2: a living systematic review and meta-analysis. PLOS Med. 2021;18:e1003735.

16. Research suggests limited risk of COVID-19 transmission from mass gatherings [Internet]. Hosp. Healthc. Eur. 2021 [cited 2021 Oct 25]. https:// hospitalhealthcare.com/covid-19/limited-risk-of-covid-19-transmissionfrom-mass-gatherings/

17. Ventilation in Buildings|CDC [Internet]. [cited 2022 Jan 14]. https://www. cdc.gov/coronavirus/2019-ncov/community/ventilation.html

18. EMG: Role of ventilation in controlling SARS-CoV-2 transmission, 30 September 2020 [Internet]. GOV.UK. [cited 2022 Jan 14]. https://www.gov. uk/government/publications/emg-role-of-ventilation-in-controlling-sarscov-2-transmission-30-september-2020

\section{Publisher's Note}

Springer Nature remains neutral with regard to jurisdictional claims in published maps and institutional affiliations.

\section{Submit your manuscript to a SpringerOpen ${ }^{\circ}$ journal and benefit from:}

- Convenient online submission

- Rigorous peer review

- Open access: articles freely available online

- High visibility within the field

- Retaining the copyright to your article

Submit your next manuscript at $\boldsymbol{\nabla}$ springeropen.com 